\title{
What's in a name? : op zoek naar de klank van woorden in het brein
}

Citation for published version (APA):

Schiller, N. O. (2004). What's in a name? : op zoek naar de klank van woorden in het brein. Maastricht University. https://doi.org/10.26481/spe.20041008ns

Document status and date:

Published: 08/10/2004

DOI:

10.26481/spe.20041008ns

Document Version:

Publisher's PDF, also known as Version of record

\section{Please check the document version of this publication:}

- A submitted manuscript is the version of the article upon submission and before peer-review. There can be important differences between the submitted version and the official published version of record.

People interested in the research are advised to contact the author for the final version of the publication, or visit the DOI to the publisher's website.

- The final author version and the galley proof are versions of the publication after peer review.

- The final published version features the final layout of the paper including the volume, issue and page numbers.

Link to publication

\footnotetext{
General rights rights.

- You may freely distribute the URL identifying the publication in the public portal. please follow below link for the End User Agreement:

www.umlib.nl/taverne-license

Take down policy

If you believe that this document breaches copyright please contact us at:

repository@maastrichtuniversity.nl

providing details and we will investigate your claim.
}

Copyright and moral rights for the publications made accessible in the public portal are retained by the authors and/or other copyright owners and it is a condition of accessing publications that users recognise and abide by the legal requirements associated with these

- Users may download and print one copy of any publication from the public portal for the purpose of private study or research.

- You may not further distribute the material or use it for any profit-making activity or commercial gain

If the publication is distributed under the terms of Article $25 \mathrm{fa}$ of the Dutch Copyright Act, indicated by the "Taverne" license above, 


\section{What's in a name? \\ Op zoek naar de klank van woorden in het brein}




\section{coloton}

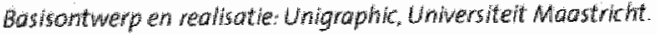

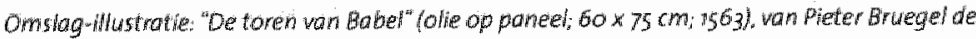
Oudere (1525-1569). Muteum Bohmons Won Beuningen, Rotherdam

PSB

NURTY

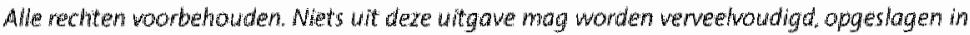

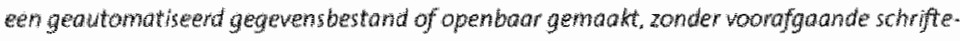
lyke toestemming wan de antew of uitgever. 


\section{What's in a name? Op zoek naar de klank van woorden in het brein}

\section{Rede}

uitgesproken bij de aanvaarding van het ambt van bijzonder hoogleraar "Psycholinguistiek in het bijzonder Fonologisch Encoderen" aan de Universiteit Maastricht,

op vrijdag 8 oktober 2004

door

Prof.. dr. Niels O. Schiller 
Mijnheer de Rector Magnificus.

geachte toehoorders,

\section{Proloog: Een tafel is een tafel}

Waarom heten dingen zo als ze heten? Waarom heet een tafel "tafel" en een bed "bed"? Deze vraag heeft iedereen zich wellicht ooit gesteld. Ik vind het een interessante wraag. De Zwitserse auteur Peter Bichsel laat in zijn kinderverhaal getiteld "Ein Tisch ist ein Tisch" (1969) een oude man voorwerpen andere namen geven omd at hij behoefte aan een verandering in zijn leven heeft. Hij besluit op een gegeven moment "wekker" tegen de stoel te zeggen, "stoel" tegen de spiegel "krant" tegen de kast, enzovoort. Op gegeven moment klonk de taal van de oude man als volgt:

"Am Morgen blieb der alte Mann lange im Bild liegen, um neun läutete das Fotoalbum, der Mann stand auf und stellte sich auf den Schrank, damiter nicht an die Füße [sic] fror, dann nahm er seine Kleider aus der Zeitung, zog sich an, schaute in den Stuhl an der Wand, setzte sich dann auf den Wecker an den Teppich, und blätterte den Spiegel durch, bis er den Tisch seiner Mutter fand."

Wat zou er gebeuren als we voorwerpen andere namen gaven? In Bichsel's verhaal loopt het niet goed af met de oude man. Hij raakt in isolement want niemand begrijpt hem meer. Namen van woorwerpen zijn woorden die in een bepaalde context gebruikt worden en een bepaalde betekenis hebben. De betekenis is gebaseerd op een overeenkomst in een culturele samenleving. Binnen deze samenleving begrijpt men wat een bepaald woord betekent. De Duitse woorden "Schlachter", "Fleischer" en "Metzger" bijvoorbeeld betekenen allemaal hetzelfde, namelijk "slager", maar hun gebruik wordt bepald door waar een spreker leeft en welk dialect hij of zij gebruikt (König, 1978). Maar hoe zit het nu precies met de verhouding tussen een woord - of preciezer gezegd, de klank van een woord - en zijn betekenis? 


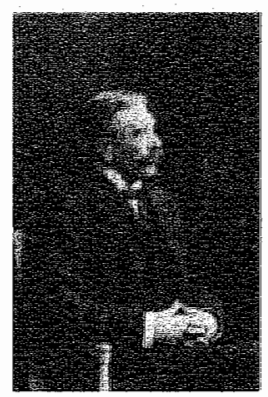

Figury Ferdinand de Soussure $(1857-1913)$

Volgens Ferdinand de Saussure (1916), de grondlegger van de moderne talkunde (zle Figuur 1), heeft een woord - of "signe" in De Saussures terminologie - een betekenis (ook "signifie" genoemd) en een vorm of klank "signifiant" bij De Saussure)." De verbinding van betekenis en klank is volstrekt willekeurig wolgens de saussure." Er is bijoorbeeld niets in de klank [bom] watop een "boom" wijst, niets in de klank [tafal] wat op een "tafel" wijst, en niets in de klamk [snaval] wat op "snavell" wijst. Warkelik niet Een blik im de Van Dale" verraadt dat woorden die met de klanken /sn/ beginnen zoals "snakken", "snoet" "snorkel" "snutfelaar" "sinult" en "snavel" vaak lets te maken hebben met de mond of de news. Zou dat toeval kunnen zijn? Mijlikt dat onwasurschijnlijk wooral als men bedenkt dat woorden die met de klanken /gl/ beginnen zoals "glans" "glimp", "glitter" "gloelen" "glunderen" en "gluren" - om maar een par te noemen - vaak lets met licht of zicht te maken hebben. Klankbeteken is verbindingen zoals tussen / sn/ en mond of neus en tussen $/ \mathrm{gl} / \mathrm{en}$ licht of zicht worden "fomaestemen" (phonaesthemes") genoemd. Benjamin Bergen (Bergen, 2004) heeft in een recent artikel in het tijdschrift Language de psychologische - of psycholinguistische realiteit van fonaestemen door een lexicale beslissingstaak im het Engels aangetoond. Bij een lexicale beslissing wordt de proefpersoon gevragad an te geven of een reeks letters wel of niet een Nederlands woord vormt. Bergen (2004) vond dat prime-target fonaestemen een hoger priming effect opleverden, dat wil zeggen relatief sneller herkend

"he signe linguistique unit [...] un concept (signifiel et une image acoustique Isigmifiant" (De Saussure, Cours de limguistique Generale, 1916, p. 98)

"te signe Inguistique est arbitraire" (De Saussure. Cours de unguistique Genetale, 1916, p. 100)

- Vam Dale - Groot woordenboek hedendaggs Nederlands (2002). Utrecht. Antwerpen: Van Dale Lexicografie. 
werden, dan woorden die alleen wormgerelateerd of alleen semantisch gerelateerd waren of woorden die semantisch an vormgerelateerd (zogenaamde pseudo-fonastemen) of helemal geen relatie hadden, de zogenaamde baseline conditie (zie Figuur 2). Maar nu heeft De Saussure een probleem want fonaestemen ondermijnen de willekeurigheid van betekenis en klank. Bergen's onderzoek toont aan dat de vorm van woorden wel belangrijk is voor hun verwerking. Woorden zijn niet arbitrair.

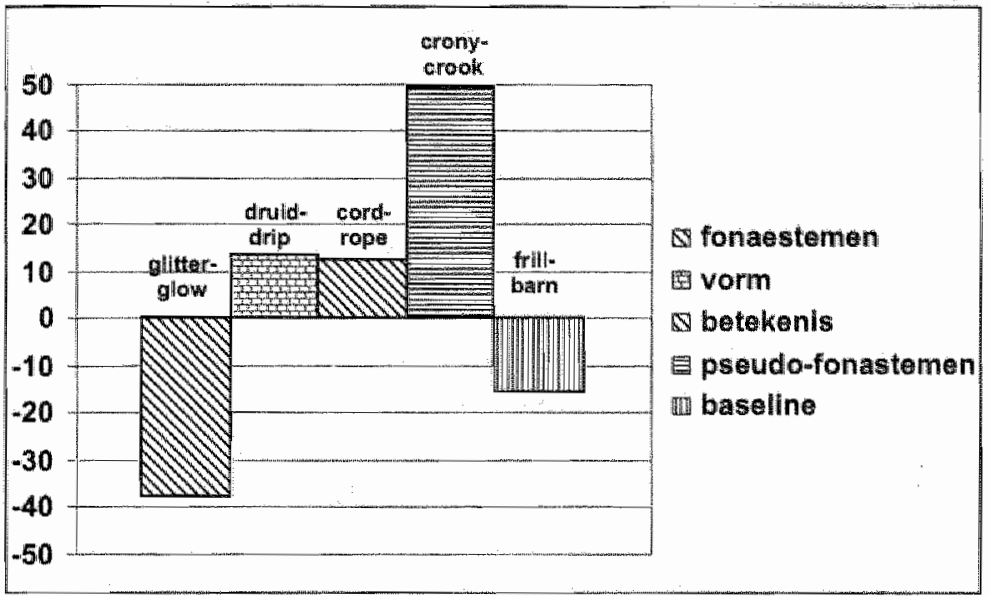

Figuur 2. Priming effekten (priming - isolatie) in milliseconden (Bergen, 20044).

Een ander voorbeeld komt uit het Duits. Hier zijn woorden die met de klanken $/ \mathrm{kn} /$ beginnen vaak mannelijk van geslacht zoals: "Knall", "Knebel", "Kniff", "Knödel" en "Knoten" bijvoorbeeld (Köpcke \& Zubin, 1984). Sprekers van het Duits gebruiken dit soort fonologische regelmatigheden tijdens de verwerking van woorden. Als hen gevraagd wordt aan te geven welk grammaticaal geslacht een woord heeft, zijn ze bij woorden die een fonologische markering hebben, in dit geval de klanken $\mathrm{kn} /$ in het begin zoals in "Knoten" sneller dan bij woorden zonder een fonologische markering en ze maken ook minder fouten bij/ $/ \mathrm{kn} /$ woorden dan bij andere woorden (Schiller, Münte. Horemans, \& Jansma, 2003.) Het effect van de fonologische markering kun je in de tijd verder preciseren als je naar het electroencephalogram of EEG signaal kijkt. Bij een EEG experiment krijgt de proefpersoon een soort badmuts op met daarin vastgemaakt hoofdelektroden. Deze elektroden meten de elektrische activiteit van bepaalde zenuwcellen in de cortex als de proefpersoon een experimentele taak uitvoert. Het EEG-signaal wordt eerst ver- 
sterkt en dan in kleine stukjes geknipt. Signalen die bij dezelfde experimentele condite horen worden gemiddeld. Op die manier raak je alle toevallige ruis in het signaal kwijt en wat over blijft is de zogenaamde ERP, of event-related potential. Nu kun je bepaalde componenten in het ERP signaal uit verschillende experimentele condities met elkaar vergelijken. Hier ziet u de verschillen in de grootte en timing van de zogenaamde $\mathrm{N}_{2} 00$ tussen $/ \mathrm{kn} /$-woorden en andere woorden op vier hoofdelektroden (zie Figuur 3; voor detalls zie Schiller et al., 2003). Het effekt dat $/ \mathrm{km} /$-woorden een andere elektrofysiologische signatuur leweren dan andere woorden, omdat ze over het algemeen mannelijk zijn, kan net zo min toeval zijn als het feit dat roofdieren, een semantische categorie dus, meestal mannelijk zijn in het Duits (bijwoorbeeld "Tiger", "Löwe" "Wolf", "Fuchs" en "Hecht"). Bloemen, daarentegen, (bijvoorbeeld "Aster", "Hortensie", "Orchidee" en "Rose") en fruit (bijvoorbeeld "Kiwi". "Mango" "Birne", "Ananas" en "Litschi") zijn meestal vrouwelijk.

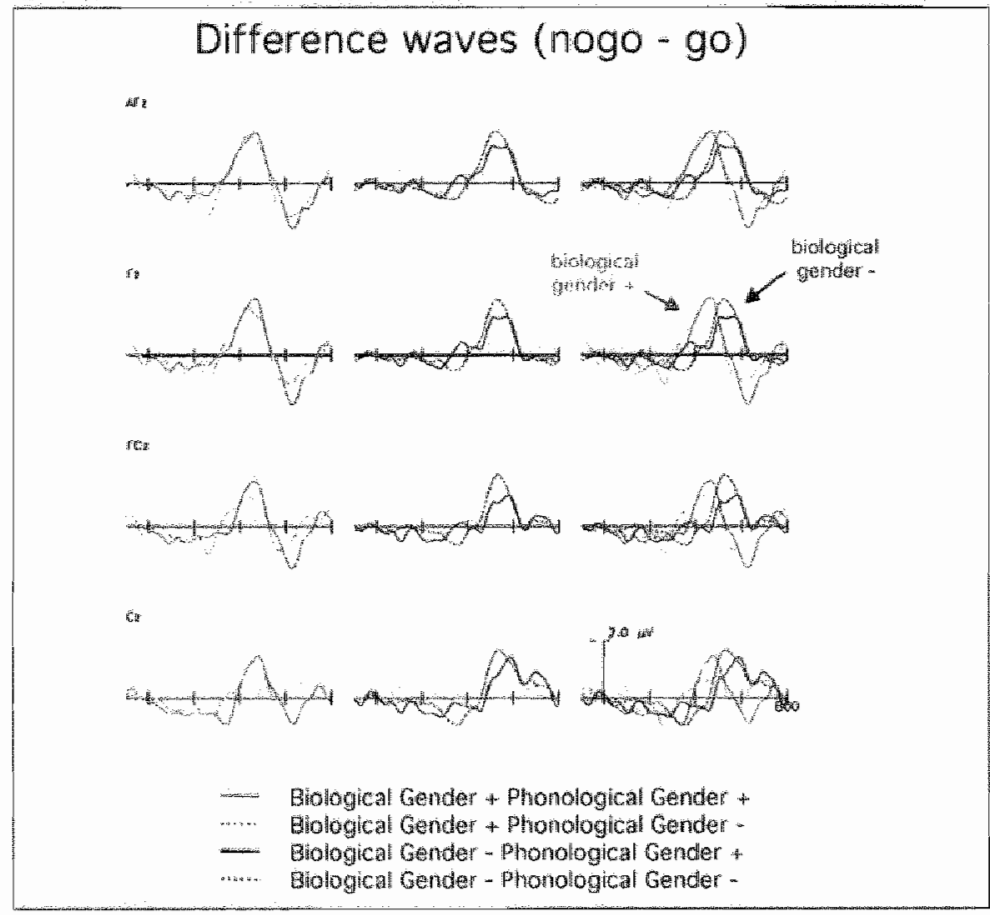

Figur 3. ERP difference woweforms (no go - go) with differences in N2O0 latency and amplitude (schiller et al. 2003). 
Ook dit is geen toeval, wooral als men bedenkt dat het Dutse gendersysteem vroeger - en nu praat ik over een paar duizend jaar - een vol functionerende grammaticale categorle was, die gebrulkt werd om betekenisverschillen duidelijk te maken. Als voorbeeld noem ik hier de door Lehmann (1958) gereconstrueerde Indo-Europese vormen "himah" (vrouwelijk: "winter"). "himäs" (mannelijk; "koud") en "himam" (onzijdigi "sneeuw"). Zelfs in het zogenaamde Oud-Hoog-Duits - gesproken tussen 750 en 1050 (Eggers, 1991) na het begin vam onte jaartelling - bestonden er nog zelfstandige naamwoorden met verschillende grainmaticale geslachten (Leiss, 1999) zoals "bluomo" (mannelijki "bloem") en "bluome" (urouwellik; "bloesem"). Ook tot deze informatie over geslachtsvoorkeuren in semantische categorien hebben sprekers toegang. 20 blijkt uit een studie die ik samen met Beate Schwichtenberg. (Schwichtenberg \& Schiller, 2004) heb uitgevoerd. We hebben twee in het Duits niet-bestaande woorden samen met een lidwoord dat het grammaticale geslacht duidelijk maakt - namelijk of "der" of "die" - aan sprekers van het Duits voorgelegd en aan hen gevraagd aan te geven welk niet-bestaand woord eerder de naam van een roofdier zou kunnen zijn. Proefpersonen hebben significant vaker het niet-bestaande woord gekozen met het mannelijke lidwoord. Precles het tegenovergestelde resultaat hebben we gevonden wanneer we dezelfde niet-bestaande woorden met dezelfde lidwoorden hebben aangeboden en aan proefpersonen gevraagd hebben welk niet-bestaand woord eerder de naam van een fruit zou kunnen zijn. Tenslotte zijn proefpersonen onbeslist als ze voor dezelfde niet-bestaande woorden moeten aangeven welk pseudowoord eerder de naam van een lichaamsdeel zou kunnen zijn. Lichaamsdelen zijn niet gemarkeerd voor een bepaald grammaticaal geslacht en proefpersonen hebben dan ook geen voorkeur voor het ene of andere geslacht (zie Figuur 4).

Wat wil ik hiermee nu zeggen? Ik vraag me af of het linguistische teken, dat will zeggen het woord, werkelijk compleet arbitrait is, zoals de Saussure ons verzekert. Misschien is het tijd dat wij als onderzokkers eens goed over de willekeurigheid van het woord gaan naden* ken. Al bijna honderd jaar wordt de linguistiek door De Saussure's dogma gedomineerd zonder dat veel aandacht wordt besteed aan bovengenoemde "uitzonderingen". Uit recent onderzoek wordt ech. ter duidelijk dat zogenaamde "witzonderingen" vaak systematisch zijn. Er zijn vele regelmatigheden tussen de betekenis en de vorm van een woord te ontdekken als je mar goed genoeg kijkt. Alleen ont. 


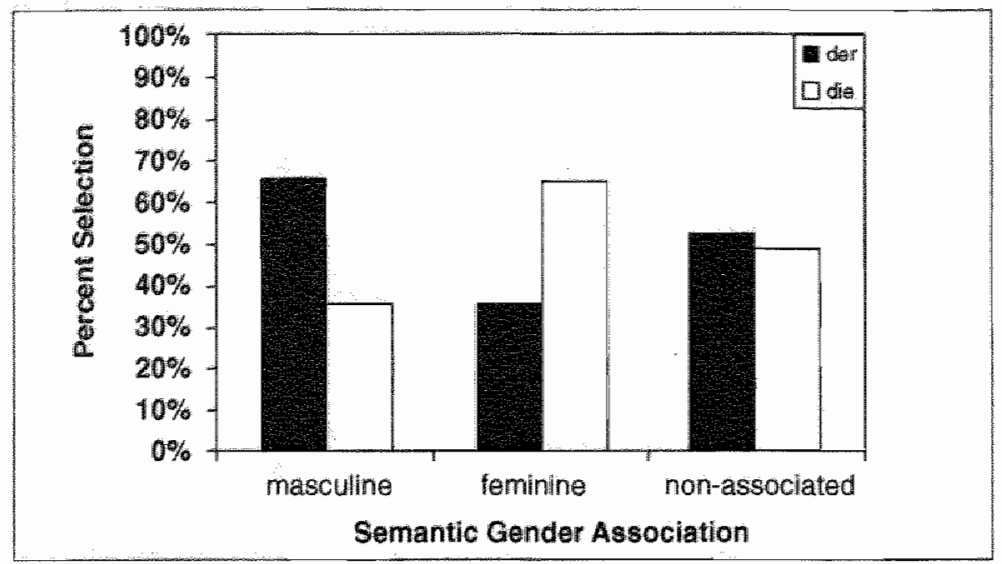

Figuur 4. Geslach tsselectie woor psewalowoorden bij mannelijke, wrowwellike en niet geassacleerde sernontische categoneen (Schwichtenberg \& Schilher, 2004).

breekt er op dit moment nog een theorie om deze regelmatigheden te verklaren.

Om een fenomeen te kunnen verklaren heeft men een theorie nodig. Een theorie doet - valk met behulp van een model - bepaalde voorspellingen en genereert nieuwe hypothesen die men dan weer empirisch kan toetsen. Wat er kan gebeuren als er geen theorie beschikbaar is om een bepaald fenomeen te verklaren beschrijft could (1977) in zijn boek "Ever since Darwin" aan de hand wan het voorbeelid van de continentendrift. Aan het begin wan de vorige eeuw probeerden geologen de distributie van verwante fossielen die op verschillende continenten werden gevonden te verklaren met de continentendrift, het bewegen van de continenten op de oppervlakte van de aarde (Wegener, 196.6). Maar er was geen mechanisme dat deze bewegingen kon verklaren, er ontbrak een theorie. Daarom werd de contimentendrift lange tijd als absurd verklaard. Pas toen nleuw bewijs over de grond van de oceanen werd verzameld, ontstond de theorie van de platentektoniek. Deze theorie stelt dat de oppervlakte van de aarde uit minder dan tien grote platen bestaat die bewegen doordat het binnengedeelte wan de aarde heet materiaal naar buiten drukt of doordat koud materiaal na ar binnen valt. De continenten zitten op deze platen vast en bewegen met hen mee. De continentendrift wordt dus verklaard door de theorie wan de platentektoniek.

Net als de aarde is ook onze taal een natuurlijk, dynamisch systeem. Nieuwe woorden ontstaan doordat sprekers ze nodig hebben, oude 
woorden verdwijnen omdat sprekers ze niet meer gebruiken. Niet het woordenboek of de grammatica maakt de taal, maar andersom, het woordenboek en de grammatica worden gemaakt door de taal en beschrijven deze vervolgens. Volgens de taalkundige Talmy Givón is "de grammatica van vandaag de conversatie van gisteren" (geciteerd uit het NRC Handelsblad van $18 / 19$ september, 2004). Taal is een weerspiegeling van menselijk gedrag, en als gedrag werandert, verandert ook de taal. Helaas zijn er tot nu toe maar weinig wetmatigheden ontdekt die beschrijven hoe taal verandert in de loop der tijd - een uitzondering is bijvoorbeeld de wet van Zipf (1935) - maar deze wetmatigheden heb je voor een echte theorie wel nodig. Toch ben ik er van overtuigd dat er maar weinig dingen toevallig zijn ontstaan in onze taal. Daarom hoop ik dat er ooit een theorie gaat komen die zogenaamde "uitzonderingen" van de willekeurigheid van de klank-betekenis verbinding op een plausibele wijze zal verklaren.

\section{Narratio: Fonologisch encoderen}

Maar ik ga veel te diep in op lets wat eigenlijk helemaal niet de kern van dit verhaal zou zijn. Laten we aan het begin beginnen. "im Anfang war das Wort" (Johannes 1,1) - zo staat het al in het evangelie na Johannes. Woorden hebben een betekenis en een klank, zoveel staat vast. En beiden moeten we ergens in ons brein opslaan, in het zogenaamde mentale lexicon dat deel uit maakt van ons lange termijn geheugen. Duizenden woorden hebben we in ons mentale lexicon opgeslagen en bimen fracties van een seconde zijn we in staat het juiste woord eruit te halen en uit te spreken. Normal gesproken begint spreken bij de betekenis. Het is vrijwel altijd handiger eerst over de inhoud na te denken en dan pas te beginnen met spreken dan andersom. Sprekers willen betekenis aan een luisteraar overbrengen, en om de inhoud van een boodschap over te brengen wordt gesproken (of geschreven of gebaren) taal gebruikt. Bij het spreken gebeurt de eigenlijke transmissie van het signaal met behulp van kanken: reekser van combinaties van medeklinkers en klinkers.

Maar hoe kom je nu aan de klank van een woord als je de betekenis hebt? Dit vind ik een boeiende vraag die mij al meer dan tien Jaar bezig houdt. En de vraag geeft ook het onderwerp van mijn onderzoeksgebied weer, namelijk fonologisch encoderen. Fonologisch encoderen maakt deel uit van het proces van taalproductie. Het proces van taalproductie 


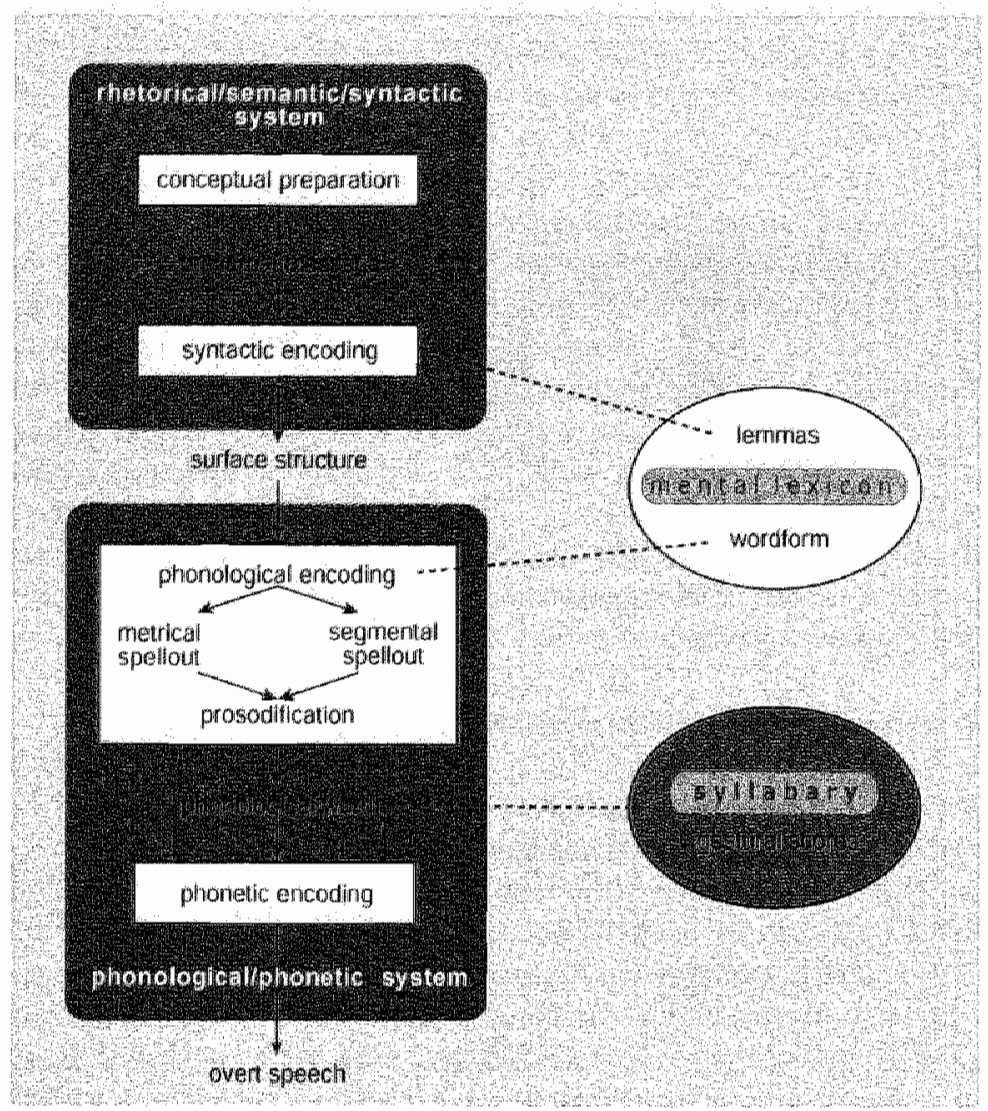

Figuur s. Het sproakproductiemodel van Levert, Roelofs en Meyer (1999).

kan worden onderverdeeld in verschillende subprocessen zoals de conceptualisatie van een idee, het zoeken en vinden van het juiste woord in ons mentaal lexicon, het grammaticaal encoderen, en tenslotte de articulatie. Voor dit laatste proces - de articulatie - valt het proces van fonologisch (en fonetisch) encoderen. Gellukkig hebben we al enigszins een idee over deze processen dankzil] theorieen en modellen over taalproductie (e.g. levelt et al., 1999) [zie Figuur 5].

Argumentatio: Op zoek naar de vorm van woorden in het brein

De eerste theorieen over taalproductie in de moderne psycholinguistiek zijn al 30 tot 40 jaar geleden ontwikkeld op basis van onderzoeken 
naar versprekingen zoals het model wan Fromkin (197) dat $u$ hier ziet en er zijn sommigen hier onder ons die dit begin persoontijk mee hebben gemaakt. Sigmund Freud (1904) zag versprekingen in zijn tijd nog. als uitingen van het onderbewuste, de zogenaamde "Freud'sche versprecher". In zijn verhandeling "Zur Psychopathologie des. Alltagslebens" geeft Freud het woorbeeld wan een psychoanalytische verklaring van een verspreking bij een arts die na de anamnese tegen de patient zei: "Was da alles zum vorschwein [in plaats van vorschein] kommt". Volgens Freud toont deze verspreking aan dat de arts eigenlijk denkt dat zijn patiënt een "Schwein" is. Maar dit soort interpretaties zijn natuurlijk altijd post hoc, en ook al beweert Freud dat simpele klankverwisselingen vaak teruggevoerd kunnen worden naar lets onderbewusts. is zijn theorie niet in staat om de verdeling van soorten van spreekfouten te voorspellen wat een goede theorie wel zou moeten kunnen (zie bijwoorbeeld de theorie van Dell, 1986). Ongeveer op hetzelfde moment dat Freud zijn verhandeling schreef, publiceerden kudolf Meringer en Carl Mayer (1895) een collectie van versprekingen en gaven een mechamistische verklaring woor versprekingen. Meringer (1908) gaf een classificatie van versprekingen die puur gebaseerd was op vormaspecten. De systematiek en regelmaat vielen hem op, waaruit hij concludeerde: "Der Zufall ist beim Versprechen volkommen [sic] ausgeschlossen, das versprechen ist geregelt."

ledereen verspreekt zich wel eens, maar sommige mensen zijn berucht voor hum versprekingen, zoals de huidige president van de $V S_{\text {; }}$ George W. Bush. Bijna vier jaar geleden zei hij bijvoorbeeld "They misunderestimated me". Deze verspreking van Bush wordt "blend" genoemd omdat de klanken van twee woorden die tegelijkertijd geactiveerd waren, namelijk "misunderstood" en "underestimated", met elkaar vermengd werden waarbij de morfeemgrenzen van de woorden netjes gerespecteerd werden. Bush's versprekingen zijn zo berucht dat men inmiddels al van "Bushisms" spreekt die men op websites na kan lezen. Ongeveer honderd jaar eerder gaf de Britse 'Reverend William Archibald Spooner (1844-1930) in Oxford les. Spooner stond ook bekend om zijn versprekingen. Ooit zou hil tegen een student hebben gezegd: "You have hissed all my mistery lessons, and in fact tasted the whole worm. I must insist that you leave by the next town drain". Dit soort verwisselingen van klanken aan het begin wan twee woorden worden daarom nog steeds "Spoonerisms" genoemd. Spoonerismen worden gekenmerkt doordat ze meestal in hetzelfde zinsdeel optreden in woorden die tot verschillende syntactische woordklassen behoren, zoals "missed" (een 
werkwoord) en "history" (een zelfstandig naamwoord) of "down" (een bligewegd nalamwoord) en "train" (een zelfstandig naamwoord). spoonerismen, oftewel foneem of klankverwisselingen, onderscheiden zich in belangrijke aspecten van woordverwisselingen zoals de volgende ("laboratory in my own computer"; Fromkin, 1971). Woordverwisselingen treden meestal op tussen werschillende syntactische zinsdelen. maar de woorden die verwisseld worden behoren tot dezelfde syntactische woordklasse, bijvoorbeeld "laboratory" en "computer" (allebel zelfstandige naamwoorden). Dit verschil heeft Merrill Carrett $(1975.1982)$ al dertig jaar geleden opgemerkt. Al in 1975 heeft Garrett de verdeling van klank = en woordverwisselingen geteld en als volgt geinterpreteerd: woordverwisselingen gebeuren op een hoger of vroeger niveau binnen het talproductieproces dan Spoonerismen. Woordverwisselingen vinden plaats op het niveau van syntactische planning of syntactisch encoderen, wanneer nog syntactische informatie over de woorden beschikbaar is zoals de syntactische woordklasse. Daarom hebben woordverwisselingen meestal dezelfde syntactische woordklasse, bijvoorbeeld zelfstandig naamwoord. Klankverwisselingen of Spoonerismen echter treden pas later in het proces op wanneer de klankinformatie over woorden wel beschikbaar is - bijwoorbeeld of een foneem een klinker of een medeklinker is - maar de syntactische informatie niet meer. Daarom komen Spoonerismen ook voor in woorden wan verschillende woordklassen zoals de woorbeelden eerder lieten zien. Als je dus aanneernt dat woordverwisselingen op syntactisch niveau ontstaan, en klankverwisselingen op fonologisch niveau - zoals de theorle van Garrett (1975) - kun je het patroon van woord-en klankverwisselingen verklaren. Met andere woorden, dit soort versprekingen maakt duidelijk dat er verschillende niveaus van planning zijn als het erom gaat spraak te produceren. Freud zou gelijk kunnen hebben dat het onderbewuste vaak de bron is van versprekingen, maar hoe de verspreking tot uiting komt. wordt bepaald door psycholinguïstische principes. Spoonerismen laten bijwoorbeeld zien dat de klank van een woord niet als geheel in ons brein is opgeslagen. Een woord wordt stuk woor stuk, foneem voor foneem of klank woor klank opgebouwd voordat we het kunnen uitspreken. Als woorden in hun geheel waren opgeslagen in het brein, zouden er geen spoonerismen of andere versprekingen op klankniveau kunnen woorkomen.

Inmiddels is er ook experimentele evidentie voor het feit dat woorden uit kleinere eenheden worden opgebouwd. Tegenwoordig gaat men ervan uit dat deze eenheden klanken zijn, fonemen of segmenten dus. In 


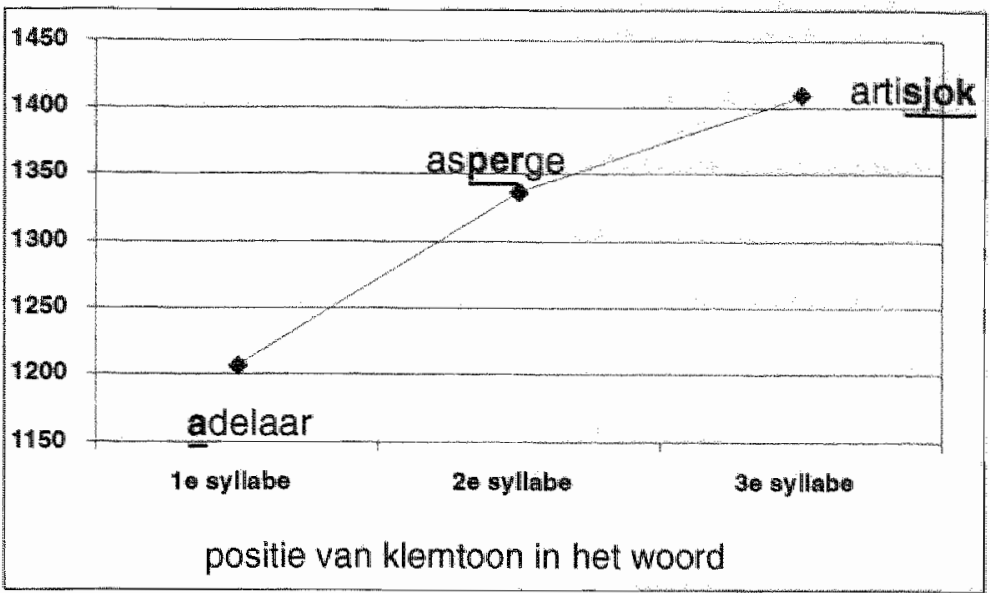

Figuur 6. Beschikbaorheld van metrische informatie (schiller et al. in drukl.

een experimentele studie liet Antje Meyer (1991) zien dat woorden klank voor klank van het begin tot het einde worden opgebouwd. Meyer liet proefpersonen woorden produceren die of in de eerste klank overlapten (bijvoorbeeld "hut", "heks", "hiel", etc.) of in de eerste twee klanken (bijvoorbeeld "hamer", "haring", "hagel") of in de eerste drie klanken (bijvoorbeeld "haver", "haven", "havik") of in de laatste klanken (bijvoorbeeld "haard", "paard", "baard", etc.). Deze condities werden homogene condities genoemd. De homogene condities werden vergeleken met heterogene condities die uit woorden bestonden die niet met elkaar overlapten, afkomstig uit verschillende homogene sets. Reactietijden, dat wil zeggen de tijd die nodig was om een woord uit te spreken, waren korter wanneer het begin van woorden kon worden voorbereld maar niet wanneer het einde van woorden kon worden voorbereid. De grootte van dit voorbereidingseffect hangt af van de grootte van de overlap tussen de woorden of - anders gezegd - hoe groot het stuk van het woord is dat wel kan worden voorbereid. Hoe meer fonemen overlappen tussen de woorden in een set, hoe meer er kan worden voorbereid en hoe sneller de reactietijden. Elk foneem dat kan worden voorbereid maakt de reactietijd weer lets korter. Het feit dat dit alleen woor klanken aan het begin van woorden geldt, maar niet voor klanken aan het einde van woorden. betekent dat woorden heel strikt van het begin naar het einde toe worden gepland. Als het begin van een woord niet bekend is, kan niet worden begonnen met voorbereiden. Er zijn inmiddels ook aanwijzingen dat metrische informatie van woorden, zoals de klemtoon, eerder 
beschikbaar is wanneer deze op de eerste lettergreep val (bijvoorbeeld "adelaar") dan wanneer deze op de tweede (bijvoorbeeld "asperge") of derde lettergreep (bijwoorbeeld "artisjok") valt (Schiller, Jansma, Peters, \& Levelt, in druk) [zie Figuur 6]. Dat la latste effect werd ook met behulp van EE data in een monitoring experiment gevonden (Schiller in voorbereiding).

Meer on-line evidentie woor het sequentielle voorbereiden van klanken tijdens de productie wan spraak komt wan een studie van Van Turennout en collega's (Van Turennout, Hagoort, \& Brown, 1997). Deze auteurs hebben proefpersonen gevragd plaatjes te benoemen. Wanneer er een kader om het plaatje heen verscheen, hadden proefpersonen de taak eem drukknoprespons te geven. Proefpersonen moesten met de linkerhand drukken wanneer het plaatje een dier was (bijwoorbeeld een tijger of een spinj en met de rechterhand wanneer het platje een voorwerp was ibijwoorbeeld een tafel of een schoen). Maar proefpersonen moesten alleen drukken wanneer de eerste klank van de plaatjesnaam een / $t$ / was (zoals bij tijger of tafel) en niet drukken wanneer het een /s/ was (zoals bij spin of schoen). Tijdens deze taak werd het EEG-signaal gemeten en de zogenaamde Lateralized Readiress. Potential of LRP berekend die op het "Bereitschaftspotential" (Kornhuber \& Deecke, 1965) gebaseerd is, een motorische component dus die vóór een drukknoprespons zichtbaar wordt. Gevonden werd dat ook bij de no-go conditie een LRP ontwikkelde dat na 40 ms weer naar de baseline terugviel. Proefpersonen hebben dus wel even een respons voorbereid, ook toen ze geen respons hoefden te geven (Van Turennout et al., 1997). In een ander experiment in dezelfde studie werden proefpersonen gevraagd op de laatste klank in een woord te reageren. Ze werden gevraagd te drukken wanneer de laatste klank een /rf was (zoals in tijger of schaar) en riet te drukken wanneer het een $/ n /$ was (zoals in spin of schoen), In dit laatste experiment wiel het no-go LRP pas na $120 \mathrm{~ms}$ naar de baseline terug. Je kunt uit deze data afleiden dat het encoderen van het laatste foneem gemiddeld ongeveer $80 \mathrm{~ms}$ langer duurt dan het encoderen van het eerste foneem voor de woorden die in deze studlie zijn gebruikt.

Een belangrijke theoretische kwestie die zich voordoet is waarom de klanken van woorden niet als geheel, dat wil zeggen als eenheid, in ons brein zijn opgeslagen? Als we niet klank voor klank aan elkaar zouden moeten rijgen woordat we een woord kunnen uitspreken, zouden we geen versprekingen meer op klankniveau kunnen maken. We zouden 
dan weliswalar geen Spoonerismen per ongeluk kumnen produceren. maar het maken van plezierige versprekingen kan niet als verklaring dienen voor de evolutie van een mechanisme dat woorden klank woor klank of foneem voor foneem laat opbouwen. Maar wat is dan de functie hiepvan? Net als bij de continentendrift wordt ook dit fenomeen plausibel als men het in de context van een theorie ziet. De theorie is de talproductietheorie van Levelt en collega's (Levelt et al., 1999). Volgens deze theorie worden klanken en metrische informatie van woorden on aflankelijk van elkaar opgezocht. Zodra beide typen van informatie beschikbaar zijn, worden ze weer met el kaar verbonden. Elke klank wordt werbonden met een bepaalde positie in een bepaalde lettergreep. Maar de eenheid is op dat moment niet meer het lexicale woord maar het fonologische woord. Bijwoorbeeld vormen de twee lexicale woorden "kook" en "ik" samen éen fonologisch woord. Daarbij komt het regelmatig voor dat klanken van lettergreep wisselen. In thet zinsdeel "vanavond kook ik" /ko.kk/ bijwoorbeeld "springt" de laatste / $/$ / van "kook" naar de volgende lettergreep. Het pronomen " $i k$ " gaat samen met het werkwoord "kook" en vormt een eenheid.

Talen hebben de universele tendens het begin van lettergrepen zo groot mogelijk te maken (onset maximization). Daarom zeggen we niet "kook ik"/kok.k/ maar "ko kik"/ko.kik/. Dit fenomeen wordt ook resyllabificatie genoemd, de syllaben - of lettergrepen - worden opnieuw gevormd. De syllabestructuur van het fonologisch woord verschilt van die van de lexicale woorden. In sommige talen is dit geinstitutionaliseerd-bijwoorbeeld door de regel woor "liaison" in het Frans. Dit is van belang als het erom gaat het spreken ergonomisch te maken en de uitspreekbaarheid van woorden in verschillende contexten te verhogen. Dit is alleen maar mogelijk omdat we elk woord voor het uitspreken klank voor klank aan elkaar rijgen en de klanken flexibel eén voor één aan lettergrepen toewijzen (Levelt et al., 1999). Deze theoretische aanname verklaart waarom wersprekingen op klankniveau kunnen ont. staan. Versprekingen op klankniveau zijn - zo zou men kunnen zeggen de negatieve bijwerking van de mogelijkheid woorden in verschillende contexten optimaal uit te kunnen spreken.

Maar als de spreker nu alle klanken van een woord bij elkaar heeft en deze klanken met posities in lettergrepen verbonden zilin, is de spreker helaas nog steeds niet in staat het woord uit te kunnen spreken. De reden hiervoor is simpelweg dat de voorbereiding nog op een te vroeg niveau is blijven steken. Oftewel, er moet nog een hoop gebeuren voordat een geprosodificeert fonologisch woord kan worden uitgesproken. 
Oat hangt daarmee samen dat de hanken zich rog in een representalie bewnden die zillin niet leent om gearticuleerd te worden. Fonemen zinn absuate planningseenheden zonder een fysleke realiteit. Uitgesproken Kankeit daarentegen hebben een temporo-spatiale structuur in de worm van articulatorische bewegingen en akoestische golven. Een belangrijke vaag is hoe de spreker van een abstracte represtematie naar een concrete representatie wan het woord kont. Deze latste representatie moet in stat ziln articulatorisch-motorische programma's a an te sturen. Hoe dit precies werkt, darover is nog niet veel bekend. Een mogelijkheld is dat de spreker de abstracte planningseenheden gebruikt om een concretere motorische representatie te activeren. Deze concrete motorische representaties zouden lettergrepen of syllaben kunnen zijn.

Waarom syllaben? sprekers uiten geen individuele kanken. Maar wat zijn de kleinste eenheden die we dan wel uitspreken? De syllabe zou een kandidaat kunnen zijm. Een syllabe heeft een klinker en éen of meerdere medaklinkers die de klinker voorafgaan en én of meerdere medeklinkers die de klinker volgen. De medeklinkers en de klinker in een syllabe worden gecoarticuleerd, dat wil zeggen dat ze min of meer tegelijkertijd worden uitgesproken. Als je bijwoorbeeld het woord "koe" wil uitspreken. dan merk je dat je lippen al voor en tijdens het uitspreken vam de /k/ in de getulte postilie woor de /u/ staan. Dat gebeurt niet bij het woord "kat" bijvoorbeeld.

\section{Enci mag nog 25 jaar graven}

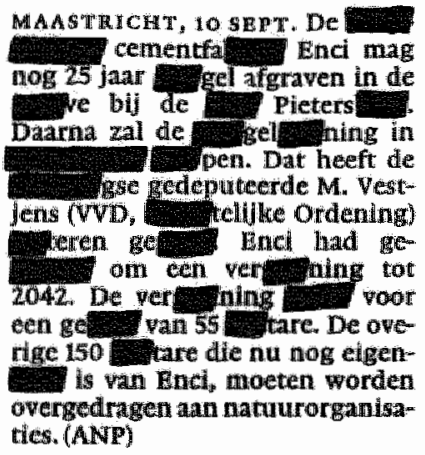

\section{Enci mag nog 25 jaar graven}

\begin{abstract}
MAAstrichT, No SEPT. De Maastrichtse cementfabriek Enci mag nog 25 jaar mergel afgraven in de groeve bij de Sint Pletersberg. Daarna zal de mergelwinning in Masstricht stoppen. Dat heeft de Limburgge gedeputeerde M. Vestlens (VVD, Ruimtelike Ordening) sisteren gezegd. Encl had gevraagd om een vergunning tot 2042. De verguning geldt voor cen gebled wan 55 hectare. De overige 150 hectare die nu nog eigendom is wan Bnct, moeten worden overgedragen aan natuurorganisaties. (ANIP)
\end{abstract}

Clguw 7 Artikel wit het NRC mandelsblad Links de origenele artikel Rechts: syllaben die net bij de 500 meest woorkomende syllaben van het Nederlands behoran zijn doorgestreept. 
Levelt en Wheeldon (1994) hebben woorden door proefpersonen laten benoemen die of uit twee veel voorkomende syllaben of uit twee weinig voorkomende syllaben bestonden. Woorden met veel voorkomende syllaben werden significant sneller benoemd worden dan woorden met weinig voorkomende syllaben. Dit resuitalt was een aanwij. zing dat syllaben-of preciezer gezegd, de motorische programma's woor het uitspreken van syllaben - apart zijn opgeslagen. De Nederlandse taal heeft zo"n 12.000 verschillende syllaben. Sommige komen wat vaken voor, andere wat minder vaak. Je zou dus kunnen aannemen dat syllaben die vaak woorkomen apart zijn opgeslagen. zo meteen ziet u een kort krantenartikel dat een aantal weken geleden in het $N R C$ verscheen. Als je nu alleen nog maar die syllaben laat staan die bij de 100 meest woorkomende syllaben van het Nederlands horen, ziet het artikel er als volgt uit. Ik geef toe dat het artikel in deze toestand niet te begrijpen is. Maar als we nu een versie zien waar alleen die syllaben blijven staan die bij de 500 meest frequente syllaben horen, is de tekst wel min of meer te begrijpen [zie Figuur 7]. Ik heb ooit berekend dat men met de 500 meest voorkomende syllaben $85 \%$ van de Nederlandse spraak zou kunnen genereren (Schiller, Meyer, Baayen, \& Levelt, 1996) [zie Figuur. 8].

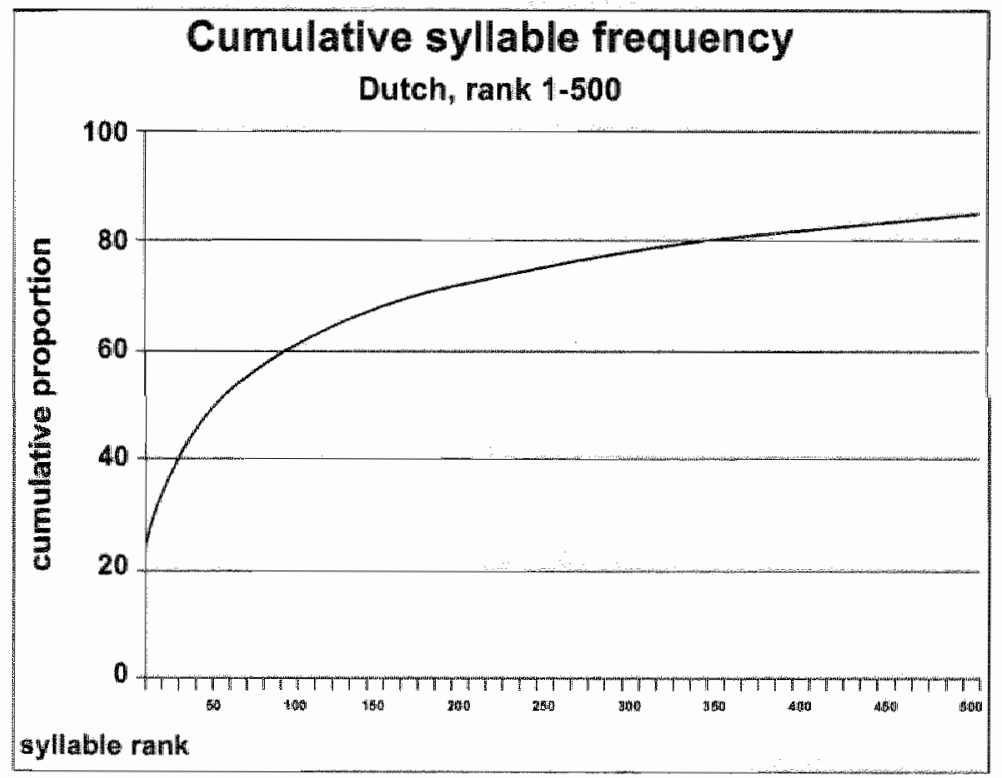

Figuur 8 . Cumulatieve syllaben frequentie voor het Nederlands ( 5 chiller et al. 9996 ). 
Hoewel er reajelijk veel off.the evidentle voor het bestaan van syllaben is - kinderen kunnen bijvoorbeeld heel vroeg a angeven hoeveel syllaben een woord bevat (Liberman, Shankweiler, Fischer, \& Carter, 1974), sprekers kunnen de syllaben van woorden gemakkelik omdraaien (Schiller, Meyer, \& Levelt, 1997, Treiman \& Danis, 1988), en veel fonologische regels zijn gebaseerd op de syllabe (Blevins, 1995; Kenstowicz; 1994) - is er helaas weinig online evidentie voor de aanname dat syllaben een functionele rol spelen tijdens de productie van spraak.

Ongeveer tien jaar geleden hebben Ferrand en collega's experimenten uitgevoerd waarbij de eerste syllabe van een plaatjesnaam gemaskeerd geprimed werd. Bij deze experimenten zag de proefpersoon aan het begin van iedere trial een reeks hekjes, gevolgd door de korte presentatie van een prime die maar $30 \mathrm{~ms}$ werd aangeboden en weer gevolgd werd door een reeks hekjes voordat een plaatje op het scherm verscheen dat de proefpersoon zo snel mogelijk moest benoemen. De prime bestond uit een medeklinker en een klinker (CV) of uit een medeklinker, een klinker, en weer een medeklinker (CVC), en was of gelijk aan de eerste syllabe van de plaatjesnaam of een klank langer of korter dan de eerste syllabe. Net hebt u een korte demonstratie gezien van de vier condities in een van de experimenten van Ferrand en collega's. Doordat de prime maar heel kort en gemaskeerd wordt aangeboden, verwerken proefpersonen de prime onbewust, dat wil zeggen tijdens het experiment nemen ze de prime niet bewust waar. Ferrand et al. (1996, 1997) vonden een syllabe-effect, zowel in het Frans als in het Engels. Helaas werden deze effecten niet gerepliceerd. In plaats van een syllabe-effect werd zowel in het Nederlands als ook in het Engels een klankeffect gevonden: Hoe meer klanken (of fonemen) geprimed worden, hoe sneller het target werd uitgesproken (Schiller, 1998, 2000) [zie Figuur 9]. Het maakte niet uit of de klanken wel of niet een syllabe vormden.

Mooi is dat, daar gaat je theorie. Dus, weg met de syllabe? Gelukkig hebben we een laatste poging gewaagd. Joana Cholin (2004) heeft in haar promotieonderzoek de syllable op een andere manier benaderd en gevonden dat syllaben weliswar niet geprimed kunnen worden, maar wel voorbereid (Cholin, Schiller, \& Levelt, 2004). Syllaben worden gevormd bij de interface tussen fonologie en fonetiek tijdens taliproductie. verder heeft ze het syllabefrequentie-effect bij pseudowoorden bevestigd (Cholin, Levelt, \& Schiller in druk), wat het idee van een mentale syllaben lexicon, welke een rol speelt tussen abstracte fonologische 


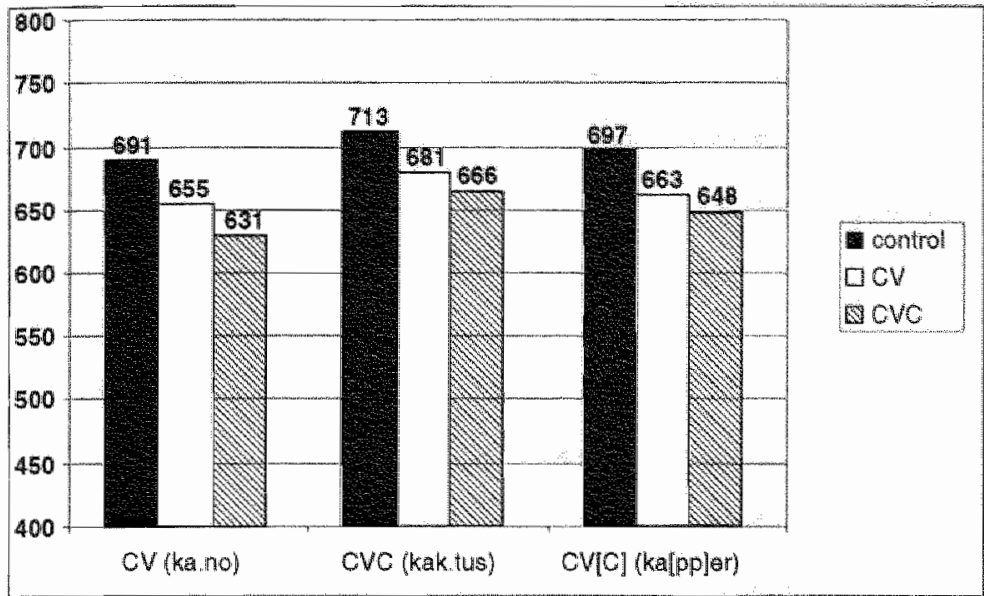

Figuur 9. Gemiddelde reactietiden (on milliseconden) per target categone (CV, CVC of $\mathrm{C}(\mathrm{C})$ ) en priming conditie (control, $\mathrm{CV}$ of $\mathrm{CVO}$ ).

syllaben en fonetische syllaben, ondersteunt. Fonetische syllaben zijn "precomplled gestural scores" dat wil zeggen van tevoren voorbereide articulatorische plannen die de uitwoering wan een articulatorischmotorisch programma controleren. Door neuro-imaging onderzoek hebben we inmiddels zelfs een woorstelling over de locatie van bovengenoemde processen in het brein en ik hoop dat ik met mijn eiger groep jonge enthousiaste wetenschappers vooral op het gebied van monitoring in de toekomst een bijdrage leveren [zie Figuur 10]. De eerste EEG en fMRI data zijn al verzameld.

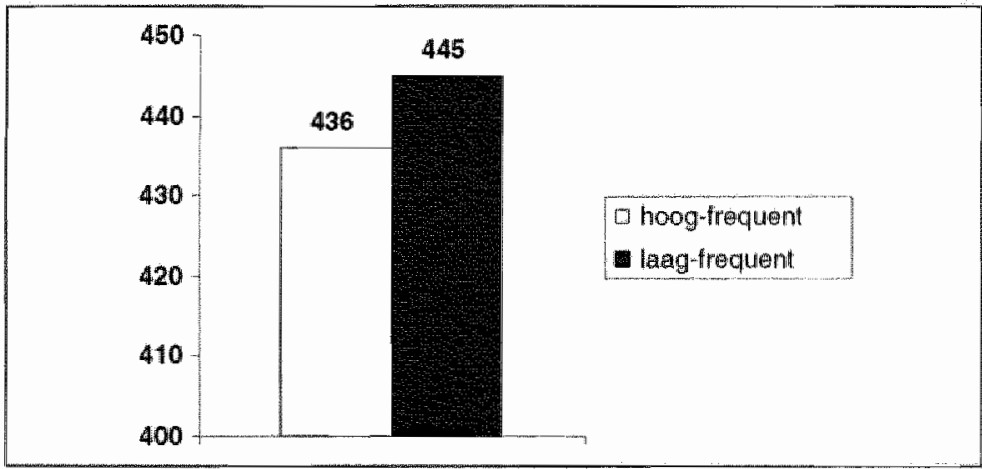

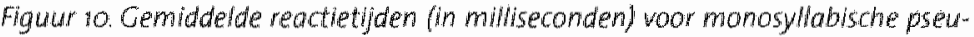
dowoorden bestainde uht hoog ws laog frequente sylloben (cholin et al, in aruk). 
Epiloog: "What"s in a name?"

\section{ROMEO}

[Aside] Shall thear more, or shall I speak at this?

\section{IULIET}

"Tis but thy name that is my enemy; Thou art thyself, though not a Montague. What's Montague? it is nor hand, nor foot. Nor arm, nor face, nor any other part Belonging to a man. 0 , be some other name! What's in a name? that which we call a rose By any other name would smell as sweet: So Romeo would, were he not Romeo calld. Retain that dear perfection which he owes Without that title. Romeo, doff thy name. And for that name which is no part of thee Take all myself.

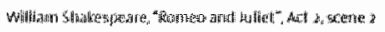

"What's in a name?" vraagt Juliet haar Romeo in de bekende balkonscène. En dan stelt ze verder dat een roos net zo zoet zou ruiken als ze een andere naam had. Maar Juliet moet wel "rose" zeggen en niet "tulip" want een tulp ruikt niet zo zoet en wat er gebeurt als je andere namen voor voorwerpen gebruikt heeft Peter Bichsel ons zien laten. "What's in a rose?" zou je dus kunnen vragen. "Rose is a rose is a rose" schreef de

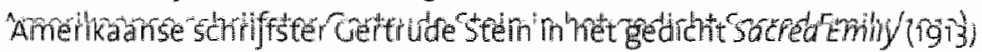
en geeft daarmee aan dat sommige dingen zich niet door woorden laten definièren. "A ROWS is a ROSE" zo de titel van een artikel van Guy van Orden (1987). In dat artikel toont hij aan dat mensen bij het stil lezen vam woorden de betekenissen van homofone woorden activeren als hun fonologle door een geschreven woord geactiveerd wordt. Zo wordt "ROWS" bijvoorbeeld a s bloem ("ROSE") beschouwd: "ROWS" activeert de fonologie van "rose" en daarom drukken mensen vaak de knop in als ze gevraagd worden te drukken wanneer ze de naam van een bloem tegenkomen. 
What's in a name? Een heleboel, zou ik zeggen. Onder andere de klank van een woord. Hoe belangrijk de klank van een woord voor het spreken is en wat een spreker moet doen om deze klank in zijn of haar brein te activeren, heb ik geprobeerd duidelijk te maken. De Saussure had ongelijk: Woorden zijn nlet arbitrair. En woor Shakespeare heb ik het volgende advies: A name is everything!

William Shakespeare

$(1564-1616)$

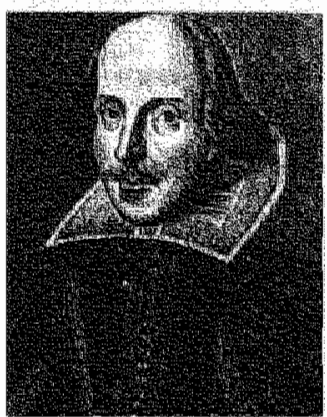




\section{Woorden van danlt:}

Hoogleraar wordt je niet in je eentje. Eigenlijk zou er een hele groep mensen samen met mij hier moeten staan die allemaal hun bijarage hebben geleverd aan het feit dat $1 \mathrm{k}$ hier vandaag mag staan. De meeste van hen zijn vandaag hier in de zaal aanwezig. Het zou helaas te lang duren iedereen te noemen maar een paar mensen wil ik wel persoonlijk bedanken.

Hooggeleerde Kóster, lieber yens-Peter.

vor 14 Jahren, im Sommersemester 1990/1991, sind wir uns zum ersten Mal an der Universität Trier im Fach Phonetik begegnet. Von Dir habe ich viel uber die Phonetik gelernt, und Du hast meine ersten wissenschaftlichen Versuche maßgeblich unterstutzt. Für diese Unterstützung, die jeder junge Wissenschaftler notig hat, und für Deine Freundschaft über all die Jahre möchte ich Dir herzlich danken.

\section{Zeergeleerde Köster, lieber Olaf,}

auch wir haben uns an der Uni Trier kennengelernt, und es klickte sofort. Wir hatten beide dieselbe Wellenlänge und hatten zusammen viel Spaß im Studium. Unser Interesse ging schon damals uber das Studienverzeichnis hinaus. Ich denke nur an diverse gemeinsame Kongreßbesuche z.B. in Aix-en-Provence, York, Stockholm, Orlando und Edinburgh, um nur einige zu nennen. Ich erimnere mich gern an jede Menge Anekdoten, die wir auf diesen Reisen erlebt haben. Wissenschaftlich trennten sich unsere Wege zwar vor zehn lahren, aber freundschaftlich hat sich nicht viel geändert. Vor allem für Deinen unverändert geistreichen Humor und Deine Freundschaft will ich Dir an dieser stelle danken.

Hooggeleerde Levelt, beste Pim.

Wat heb ik mazzel gehad toen $k$ in 1994 in jouw onderzoeksgroep aan het Max Planck Instituut in Nijmegen belandde. Het was natuurlijk puur toevallig dat ik een advertentie in "Die Zeit" heb gelezen, gesolliciteerd heb, en dan ook daadwerkelijk mijn promotieonderzoek onder jouw en Antje's begeleiding mocht uitvoeren. Voor mij waren jullie de ideale begeleiders en ik heb ontzettend veel van jullie geleerd. I bewonder nog steeds jouw vaardigheid op het juiste moment precies het goede idee te hebben. Jullie waren ook op niet wetenschappelijke manier zeer betrokken - ik herimer alleen aan al de toestanden ma mijn 
ongeluk in de zomer van 1997. Daar ben ik zeer dankbaar voor. Na mijn terugkeer uit de VS was je altijd lemand naar wie ik toe kon gaan als ik goede raad nodig had. Kortom, ik ben zeer gelukkig dat je altijo mijn mentor bent geweest en ik wil je hiervoor van harte danken. Ook in de toekomst hoop ik nog lange tjd wan jouw inspirerende invioed te mogen genieten.

Zeergeleerde Jansma, liebe Bernie,

wir haben uns als PhD-Kollegen am MPI kennengelent und viel zusammen gemacht: Niederländisch lernen, auf Konzerte fahren, in die Extase gehen. Aber zusammengehalten hat uns in erster Linie das gemeinsame interesse für unser Fach, Sprachproduktion. Schon damals in Nijmegen hast Du mir viel beigebracht, z.B. non-parametrische statistische Methoden. Auch wir haben uns nicht aus den Augen vertoren, und vor fünf Jahren warst Du diejenige, die mich nach Maastricht geholt hat - nach einem "Boxenstopp" in den legendaren Culpener Pommesbuden. Für alles, was Du für mich getan hast, ohne dabei an Dich selbst zu denken, möchte ich Dir an dieser Stelle danken.

Er zijn natuurlijk nog een hele boel andere mensen, collega's, familiew leden en vrienden die ik graag zou willen bedanken voor hun bijdrage. Helaas heb ik daar de tijd niet voor. Eén lemand wil ik alsnog speciaal noemen, en dat is mijn lieve Vivian. Vivian, je hebt mijn leven totaal veranderd, met jou ben ik gelukkig geworden en ik ben dolblij dat we elkaar ontmoet hebben - ook met dank aan Arie natuurlijk. vaak heb je geduldig op mij zitten wachten als ik nog "heel eventjes" iets af moest maken. In jou had ik altijd een goede voor praktisch advies en de laatste weken was je de enige die deze rede moest aanhoren, en niet maar een keer ook. Voor al je geduld, steun en liefde over de laatste jaren wil ik jou graag bedanken.

Ik heb gezegd. 


\section{Referenties}

Dergen, B. (2004). The psychological reality of phonaesthemes. Language, 80,230 $-31 \%$.

Bichsel, P. (1969). Ein Tsch ist ein Tisch. In Kindergeschehten Newwed/Berin: Luchterhand.

Blewirs, J. (1995). The syllable in phonological theory. In J. A. Goldsmith (ed.). The handbook of phonological theory (p. 206.244). Cambridge. MA Blackwell.

Cholin, 1. (2004). Sylables in speech production. Effects of syllable preparation and sylloble frequency. Unpublished PhD dissertation (MPI series in psycholinguistic $5 ; 26$ ).

Choln, s, Levelt, W. M. s Schiller, N. O. (in druk). Effects of sylable frequency in speech production Cognitian.

Cholin, 1. Schiller. W. O \& Levelt. W. I. M. (2004). The preparation of sylables in speech production Journal of Memory and Language, 50, 47 $6 \%$.

Dell, G. 5. (1986). A spreading-activation theory of retrieval in sentence production. Psychological Review, $93,283-321$.

De Saussure, F. (1916), cours de linguistlque generale. Paris. Payot.

Eggers, H. (1991). Dewtsche Sprachgeschichte. Band 1. Das Alhochdeutsche und das Mittethochdeutsche. Reinbelk Rowohit.

Ferrand L. Segui. J \& Crainger "I. (1996). Masked priming of word and picture naming: The role of syllable units. Journal of Memory and Langugge, 35, 708 723.

Ferrand, L., Segui, J., \& Humphreys G. W. (1997). the syllable's role in word naming. Memory \& Cognition, $25,458-470$.

Freud, 5. (1904). Zur Psychopathologie des Altagslebens. Uber Wergessen. Versprechen, vergreffen, Abergloube und Irtum (voor het eerst gepubliceerd 1901 in Berliner Monatsschrift fur Psychiatrie und Neurologie). Basel: S. KargerVertag.

fromkin. $V$. (1971). The non-anomalous nature of anomalous utterances. Language, $47,27.52$.

Garrett, M. F. (1975). The analysis of sertence production. In G.H. Bower (ed.), The psychology of learning and motivation. Advances in research and theory ( $p p$. 133-177). New York NY: Academic Press.

Garrett $M .68$. $(19)$ Levels of processing in sentence production. In B Butterworth (ed). Language production: speech and tak, wol. (pp 177-220). New Work, Nr: Academic press.

Gould, 5. 1. (1977). Ever since Darwin. Reflections in matural history. New York: Norton \& Company.

Indefrey, P. \& Levelt, W. J M. (2004). The spatial and temporal signatures of word production components. Cogmition, $92,101-144$.

Kenstowicz, M. (1994). Phonology in generative grammar Cambridge, MA: Blackwell.

König. W. (1978). Dtr.Atas zur deutschen Sproche Müncher: Deutscher Taschenbuch verlagg. 
Kopeke, K.M. \& Zubin, D. A. (1984) Sechs Prnzipien tur die Genuszuweisung in

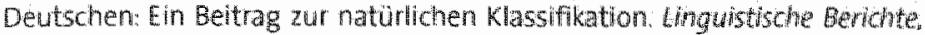
$93.26-50$.

Komhuber, H. H. \& Deecke, 1. (1965). Himpotentalanderungen bet Whlkürbawegungen und passiven Bewegungen des Menschen Bereitschaftspotential und reafferente Potentiale. Pflugers Anchiv for die gesamte Physiologle des Menschen und der Tere, 28,4, $1-17$.

Lehmann, W. P. (1958). On earlier stages of the Indo-European nominal infection. Language, $34,179-202$

Leiss, E. (1999). Gender in Old High German In B Unterbeck \& M. Rissanen (eds.) Gender in grammar and cognition (pp. 225-244). Berlin: Mouton de Cruyter.

Levelt. W. J. M. Roelofs, A, \& Meyer, A. S. (1999). A theory of lexical alcess in speech production Behaworal and Brain Sciences, $22,1-75$.

Levelt, W. J. M. \& Wheeldon. L. (1994). Do speakers have access to a nental syllabary? Cognition, $50,239-269$.

Liberman, I.Y., Shankweiler, D. Fischer, F.W., \& Carter, B. (1974). Explicit syllable and phoneme segmentation in the young child. Joumal of Experimental child Psychology, 18,201-212.

Meringer, R. (1908). Aus dem Leben der Sprache: Versprechen. Kindersprache, Nachahmungstrieb. Berlin: Behr.

Meringer, R. \& Mayer, C. (1895). Wersprechen und Werlesen, eine psychologisch-linguistische studie stuttgart: Göschen'sche Verlagsbuchhandiung.

Meyer, A. S. (1991). The time course of phonological encoding in language produc. tion: Phonological encoding inside a syllable foumal of Memory and Language, $30,69-89$.

Schiller, N. 0 . (1998). The effect of visually masked primes on the naming latencies of words and pictures Journal of Memory and Language, $39,484 \mathrm{mo7}$.

Schiller, N. O. (2000). Single word production in English. The role of subsyllabic units during speeci production. Journal of Experimental Pychology: Learming. Memory and Cognition, $26,512-528$.

Schiller, $N$. O. (in voorbereiding). ERP characteristles of metrical stress monitoring.

Schiller, N. O. Jansma, B. M. Peters, J., \& levelt. W. J. M. (in druk). Monitoring metrical stress in polysyllabic mords. Language and Cognitive Processes.

Schiller, N. O. Meyer, A. S., Baayen, R. H. \& Levelt. W. J, M. (1996). A comparison of lexeme and speech syllables in Dutch. Joumal of Quantitative Lingustics, 3,8 28.

Schiller, N. O. Meyer, A. 5. \& Levelt, W. I. M. (1997). The syllabic structure of spoken words: Evidence form the syllabification of intervocalle consonants. Language and speedt, 40,103-140.

Schiller, W. O. Munte. T. Horemans, 1. \& Jansma. B. M. (2003). The linfluence of semantic and phonological factors on syntactic decisions: An event-melated brain potential study. Psychophysiology, 40.869-877

Schwichtenberg, B. \& Schiller, W. O. (2004). Semantic gender assignment regular. ties in German. Broin and Language, $90,326 \cdot 337$.

Stein. G. (1913). Geography and Plays. Boston: Four Seas Co, 1922. 
Treman, Danis, C. (1988). Syllabification of interwacalic consonants. Joumal of Mernory and Language, $27,87-104$.

Wan Orden, C.C. (ng87). A ROWS Is a ROSE: Spelling, sound, and heading. Memory ar Cogntion. 15 181-198.

Wan Turenout, M, Hagoort, P. B Brown, C.M. (1997). Electrophysiological evidence on the the course of semantic and phonological processes in speech pro. duction. Journal of Experimentai Psychology: Leaning. Memony. and Cognition, 23,787806 .

Wegener, A. (1966) The argins of continents and oceans. New York. Dover. Zipt, G (1935) the psycho-biology of language. Cambridge, MA MT Press. 
